\title{
Elderly men's quality of life and lower urinary tract symptoms: an intricate relationship
}

\author{
Vitor Last Pintarelli, Lygia Ferreira Gomes Perchon, Fábio Lorenzetti, João Toniolo Neto, \\ Miriam Dambros
}

Division of Geriatric Urology (VLP, LFGP, FL, MD), Division of Geriatrics and Gerontology (JTN), Federal University of São Paulo, Brazil

\begin{abstract}
Purpose: To evaluate the impact of lower urinary tract symptoms (LUTS) on the quality of life (QoL) in a group of elderly men.

Materials and Methods: Observational clinical study contained 200 men recruited between March-September 2008 in the community and Urology and Geriatrics ambulatories. The data collected included health and sociodemographic conditions; the International Prostate Symptom Score (IPSS); an anxiety/depression inventory; the World Health Organization Quality of Life -Bref and -Old questionnaires (WHOQoL). Participants were classified according to IPSS: Group I (moderate/severe symptoms) and Group II (absence/mild symptoms) and 100 men were included in each group. Results: The groups were statistically similar in sociodemographic, morbidity, and anxiety/depression scores. Both QoL scales showed significant lower median scores in group I in all parameters, except the global subjective self-evaluation of QoL. The domains social and environmental relations presented the most significative differences $(p<0.0005)$ in both questionnaires, and final mean WHOQoL-Old score was lower in group I $(\mathrm{p}<0.0005)$.

Conclusions: For elderly men, moderate to severe LUTS do significantly impact almost all parameters of QoL proposed by the WHO, especially social and environmental relations.
\end{abstract}

Key words: Prostatic hyperplasia; aged; quality of life; questionnaires

Int Braz J Urol. 2011; 37: 758-765

\section{INTRODUCTION}

The conditions leading to lower urinary tract symptoms (LUTS) are among the most prevalent diseases of elderly males, with potential impairment of quality of life (QoL) (1-11). Among elderly men, benign prostatic enlargement (BPE) is the main cause of LUTS, which can be evaluated by the International Prostate Symptom Score (IPSS) (1-3,12). Among elderly men, benign prostatic enlargement (BPE) is the main cause of LUTS. Despite criticisms about its discriminatory power to predict infravesical obstruction, the International Prostate Symptom Score (IPSS) is the most used instrument to evaluate LUTS in male patients $(1-3,13)$. BPE, except in extreme cases, does not pose a major threat to one's physical integrity, but undermines QoL; for most mild and moderate-symptom patients, QoL impairment is the main parameter evaluated on whether treating BPE, and choosing therapeutic methods (1-13). Many articles attempting to evaluate the impact of LUTS and BPE on men's QoL have been published since the World Health Organization Consensus Committee recommended the association of the IPSS with QoL scales, but inappropriate interpretations of the concept of QoL in many of these studies have triggered criticisms (3,14-17). Furthermore, while BPE occurs predominantly in elderly men, and validated geriatric QoL scales do exist, no studies using such questionnaires to assess the impact of LUTS on elderly 
populations have been published. This article aims to assess the role of LUTS on the QoL in a group of elderly men.

\section{MATERIALS AND METHODS}

This was an observational clinical study conducted between March-September 2008, approved by the institutional ethics committee.

The inclusion criteria were: male sex; 65 -years aged or over; voluntary participation; understanding and signing the consent form. The exclusion criteria were: previous radical prostatectomy; use of bladder catheter; acute diseases; trauma, surgeries or hospitalizations during the preceding month; uncompensated chronic diseases; malignancies; neuropsychiatric diseases; alcoholism; drug abuse; use of psychotropics. Two hundred men (any race, schooling and social level) were selected from among Urology (90 patients) and Geriatrics (60) outpatients at a university hospital, these patient's companions (10), participants of community centers (20) and fitness programs for the elderly (20). The research protocol was composed of:

1. Sociodemographic and health conditions questionnaire;

2. International Prostate Symptom Score (IPSS) (14);

3. Hospital Anxiety and Depression Scale (HADS) (18);

4. WHOQoL-Bref questionnaire (19);

5. WHOQoL-Old questionnaire (20);

Four trained researchers conducted the interviews in private rooms, which lasted on average 40 minutes. Self-administration of questionnaires was preferred, but face-to-face interviews were conducted when the participants presented visual deficits, illiteracy or semi-illiteracy. Only 13 participants could not respond by themselves.

Sociodemographic information included age, race, marital status, schooling, religion, economic and employment status. Health conditions investigated included previous diagnoses of hypertension, diabetes and heart diseases; use of medications; practice of sports or physical activities (at least walking for 30 minutes, thrice a week).

The Hospital Anxiety and Depression Scale (HADS), also used to evaluate non-hospitalized pa- tients and individuals without disease, has 14 items, seven focusing on anxiety assessment (HADS-A), and seven on depression (HADS-D). Each of its items can be scored from 0-3, giving a maximum score of 21 points for each scale. Values $\geq 9$ positively detect the assessed symptom (18).

The questionnaires WHOQoL-Bref and WHOQoL-Old are generic instruments developed by the World Health Organization to evaluate quality of life (QoL) with cross-cultural validity and applicability. Both provide a comprehensive assessment of QoL through evaluating different parameters (termed domains and facets), such as physical health, psychological aspects, social relationships, among others. The questionnaire WHOQoL-Bref contains 26 multiple-choice questions, divided in four domains. The questionnaire WHOQoL-Old was especially developed to assess individuals aged 60 -years or over, and contains 24 multiple-choice questions, divided in six facets. In both questionnaires, the scores from responses produce a profile of QoL, which can be split into individual scores, for each of the different domains and facets examined, scaled in a positive direction (higher scores indicate higher QoL); the average scores from items within each field are used to calculate the score for the whole field, and, for the questionnaire WHOQoL-Old, an overall score can be calculated $(19,20)$.

The participants were divided into two groups, according to the IPSS results: symptoms).

Group I: Scores 8-35 (moderate/severe toms).

Group II: Scores 0-7 (absence/mild symp-

The sample size was estimated from a pilot sample, composed of the first 50 participants in each group. The loss of, in mean, 1 point per facet of the WHOQoL-Old questionnaire was accepted as clinically significant; assuming a difference of 6.5 units as relevant, with standard deviation of 14 , statistical analysis estimated that a sample of 100 participants per group would be needed for the detection of statistically significant differences between the mean total scores of WHOQoL-Old for the two groups (assuming a statistical power of $90 \%$ and a significance level of $5 \%$ ), through a bilateral hypothesis test. For statistical evaluation, 
the tests used were student's t, Brown-Mood, chisquare, and Fisher-Freeman-Halton exact test.

Every significant probability ( $p$ values) was recorded as the bilateral type, and values $<0.05$ were considered statistically significant. The SAS 9.1 software (Statistical Analysis System, Cary, NC, USA) and Minitab 14.1 (State College, PA, USA) were used for the statistical analyses.

\section{RESULTS}

The results from the sociodemographic and health conditions data are described in Table-1.
Mean ages were $72.89( \pm 5.96)$ and 73.41 $( \pm 5.95)$ years, in groups I and II, respectively $(p=$ $0.538)$. The distribution of proportions of race categories $(p=0.0932)$, schooling level $(p=0.1521)$, and diagnoses of hypertension $(\mathrm{p}=0.099)$, diabetes $(p=0.5993)$, heart diseases $(p=0.6418)$ and sedentarism $(\mathrm{p}=0.1543)$, marital status $(\mathrm{p}=0.5127)$, religious denominations $(p=0.4079)$, monthly income $(p$ $=0.9848)$, causes of inactivity $(p=0.9446)$ and use of medications $(p=0.4306)$ showed no difference.

With regard to HADS scores, the number of individuals who attained the anxiety and depression cutoff scores was exactly the same, 21 men in group

Table 1 - Main socio-demographic and health conditions results.

\begin{tabular}{|c|c|c|c|c|}
\hline \multicolumn{2}{|c|}{ Socio-demographic and health data } & \multirow{2}{*}{$\begin{array}{c}\text { Group I } \\
35\end{array}$} & \multirow{2}{*}{$\begin{array}{c}\text { Group II } \\
30\end{array}$} & \multirow{2}{*}{$\begin{array}{c}\text { Total } \\
65(32.5 \%)\end{array}$} \\
\hline Age & 65-69 years-old & & & \\
\hline & 70-79 years-old & 48 & 50 & $98(49.0 \%)$ \\
\hline & $\geq 80$ years-old & 17 & 20 & $37(18.5 \%)$ \\
\hline & Minimum & 65 & 65 & \\
\hline & Maximum & 88 & 89 & \\
\hline & Median & 72.5 & 72.5 & \\
\hline & Mean (SD) & $72.89( \pm 5.96)$ & $73.41( \pm 5.95)$ & \\
\hline \multirow[t]{2}{*}{ Ethnicity / race } & White & 70 & 74 & $144(72.0 \%)$ \\
\hline & Non-white & 30 & 26 & $56(28.0 \%)$ \\
\hline \multirow[t]{2}{*}{ Marital status } & Married & 74 & 82 & $156(78.0 \%)$ \\
\hline & Widowed & 13 & 11 & $24(12.0 \%)$ \\
\hline \multirow[t]{2}{*}{ Religion } & Catholics & 75 & 71 & $146(73.0 \%)$ \\
\hline & Protestants & 16 & 13 & $29(14.5 \%)$ \\
\hline Schooling & Primary school & 78 & 66 & $144(72.0 \%)$ \\
\hline \multirow[t]{2}{*}{ Monthly income } & $\leq 2 \mathrm{MW}$ & 48 & 44 & $92(46.0 \%)$ \\
\hline & 2-5 MW & 43 & 47 & $90(45.0 \%)$ \\
\hline \multirow[t]{2}{*}{ Inactivity causes } & Retirement & 73 & 70 & $143(71.5 \%)$ \\
\hline & Still active & 23 & 24 & $47(23.5 \%)$ \\
\hline \multicolumn{2}{|c|}{ Arterial hypertension } & 72 & 61 & $133(66.5 \%)$ \\
\hline \multicolumn{2}{|l|}{ Diabetes mellitus } & 22 & 19 & $41(20.5 \%)$ \\
\hline \multicolumn{2}{|l|}{ Heart diseases } & 31 & 28 & $59(29.5 \%)$ \\
\hline \multicolumn{2}{|c|}{ Anti-hypertensive drugs use } & 55 & 47 & $102(46.0 \%)$ \\
\hline \multicolumn{2}{|c|}{ Anti-diabetic drugs use } & 02 & 03 & $05(2.5 \%)$ \\
\hline \multicolumn{2}{|c|}{ Anti-hypertensive and anti-diabetic drugs use } & 17 & 14 & $31(15.5 \%)$ \\
\hline \multicolumn{2}{|l|}{ Sedentary } & 61 & 51 & $112(56.0 \%)$ \\
\hline
\end{tabular}

SD: standard deviation; MW: minimum wages (About US\$200.00). 
I and 8 in group II, for each of these conditions, leading to no differences in the proportions of anxiety ( $p$ $=0.0932)$ and depression scores $(p=0.0932)$.

Groups I and II presented mean IPSS 15.83 $( \pm 6.3)$ and $4.01( \pm 2.12)$ respectively. The medians for IPSS-QoL were also different between the two groups $(\mathrm{p}<0.0001)$.

The WHOQoL-Bref scores achieved for each question were transformed into a scale of one hundred points, in accordance with the syntax recommended in the manual. The statistical analysis on these responses was performed by gathering the questions relating to every QoL domain evaluated. Such results are presented in Tables 2 and 3.

The first two questions of the WHOQoLBref presented significant differences in responses only in the second question $(\mathrm{p}<0.0001)$, however the means scores from each WHOQoL-Bref domain revealed differences between the scores of: physical health $(\mathrm{p}=0.007)$, psychological aspects $(\mathrm{p}=$ $0.001)$, social relationships $(p<0.0005)$ and environment $(\mathrm{p}<0.0005)$.

Table 2 - WHOQoL-BREF Results Relative to the First Two Questions.

\begin{tabular}{lccccc}
\hline Questions & Answers & Group I & Group II & Total & p \\
\hline 1. How would you rate your quality & Very poor & 01 & 01 & $02(1.0 \%)$ & 0.0814 \\
of life? & Poor & 04 & 01 & $05(2.5 \%)$ & \\
& Neither good nor poor & 29 & 20 & $49(24.5 \%)$ & \\
& Good & 62 & 66 & $128(64.0 \%)$ & \\
& Very good & 04 & 12 & $16(8.0 \%)$ & \\
& Total & $\mathbf{1 0 0}$ & $\mathbf{1 0 0}$ & $\mathbf{2 0 0}(\mathbf{1 0 0 \%})$ & \\
2. How satisfied are you with your & Very dissatisfied & 03 & 00 & $03(1.5 \%)$ & $<0.0001$ \\
health? & Dissatisfied & 20 & 05 & $25(12.5 \%)$ & \\
& Neither satisfied nor & 28 & 16 & $44(22.0 \%)$ & \\
& dissatisfied & & & & \\
& Satisfied & 41 & 58 & $99(49.5 \%)$ & \\
& Very satisfied & 08 & 21 & $29(14.5 \%)$ & \\
\hline
\end{tabular}

Table 3 - WHOQoL-BREF Results Relative to the Four Domains.

\begin{tabular}{lcccc}
\hline Domain & Values & Group I & Group II & p \\
\hline Physical health & Mean (SD) & $56.5( \pm 10.2)$ & $60.32( \pm 9.36)$ & 0.007 \\
Psychological & Standard error & 1.0 & 0.94 & \\
& Mean (SD) & $56.2( \pm 12.0)$ & $61.5( \pm 10.0)$ & 0.001 \\
Social relationships & Standard error & 1.2 & 1.0 & $<0.0005$ \\
& Mean (SD) & $62.3( \pm 16.5)$ & $70.4( \pm 14.4)$ & \\
Environment & Standard error & 1.7 & $65.5( \pm 12.7)$ & $<0.0005$ \\
& Mean (SD) & $57.0( \pm 12.2)$ & 1.3 & \\
\hline
\end{tabular}

SD: Standard deviation 
WHOQoL-Old scores were transformed in accordance with the syntax in the manual, to compare the mean scores of every facet and produce the overall WHOQoL-Old score. The results relating to WHOQoL-Old scores are presented in Table-4.

The analysis of mean scores of the questionnaire WHOQoL-Old revealed differences between the scores obtained by groups I and II for each of the six facets, and also for the final score: sensory functioning $(\mathrm{p}=0.003)$, autonomy $(\mathrm{p}=0.003)$, past, present and future activities $(\mathrm{p}=0.001)$, social participation $(p<0.0005)$, dying and death $(p=0.003)$, intimacy $(p=0.003)$ and Old score $(p<0.0005)$.

\section{DISCUSSION}

The variety of backgrounds of participants was adopted to raise the epidemiological spectrum of the sample, so as not to restrict the investigation to patients undergoing outpatient medical care. However, it should be mentioned that this was not a true random sample of men, but patients were chosen for inclusion into the study, which allows the possibility of selection bias. The exclusion criteria were, essentially, prevalent clinical conditions that undermine QoL. Previous radical prostatectomy was an exclusion criterion because it is mainly used as treatment for prostate malignancies.

Users of bladder catheters were excluded because of the impossibility to assess LUTS through the IPSS. Previous transurethral resection of prostate, except for recent postoperative states, and the use of alpha-blockers and 5-alpha-reductase inhibitors, were not exclusion criteria, because neither prevent assessment of LUTS, nevertheless symptoms at the time of the interview could be different from those observed before such treatments.

The two groups were adequately matched to sociodemographic and health condition. Despite not statistically significant, a trend to increase in anxiety and depression scores was observed in group I. The median age was similar in the two groups (72.5 years); nevertheless it could seem a low indicator for a geriatric sample, it exceeds the 2006 WHO estimative of male population life-expectancy of this country (68.8 years), and overlaps in more than 12 years

Table 4 - WHOQoL-OLD Results.

\begin{tabular}{lcccc}
\hline Facet & Values & Group I & Group II & p \\
\hline Sensory Functioning & Mean (SD) & $14.71( \pm 3.55)$ & $15.68( \pm 3.17)$ & 0.003 \\
& Standard error & 0.35 & 0.32 & \\
Autonomy & Mean (SD) & $14.24( \pm 2.68)$ & $15.38( \pm 2.58)$ & 0.003 \\
& Standard error & 0.27 & 0.26 & \\
Past, Present and Future & Mean (SD) & $14.03( \pm 2.83)$ & $15.26( \pm 2.42)$ & 0.001 \\
Activities & Standard error & 0.28 & 0.24 & \\
Social Participation & Mean (SD) & $13.77( \pm 2.69)$ & $15.10( \pm 2.44)$ & $<0.0005$ \\
& Standard error & 0.27 & 0.24 & 0.003 \\
Dying and Death & Mean (SD) & $14.49( \pm 4.01)$ & $16.12( \pm 3.69)$ & 0.003 \\
Intimacy & Standard error & 0.40 & 0.37 & \\
Final global score OLD & Mean (SD) & $15.09( \pm 2.94)$ & $16.27( \pm 2.67)$ & 0.0005 \\
& Standard error & 0.29 & 0.27 & \\
& Mean (SD) & $86.3( \pm 12.5)$ & $93.8( \pm 11.5)$ & 1.1 \\
\end{tabular}

SD: Standard deviation 
the 60-year-old parameter, accepted in developing countries as demographic indicator for classification of elderly people.

Most of the studies performed to measure the impact of LUTS on men's QoL evaluate pharmacological and surgical treatments for BPO, and largely adopt expressions like "quality of life" and "healthrelated quality of life", since most of the authors believe that the impairment of QoL due to LUTS is a key measurement to assess the effectiveness of any treatment for BPO $(1-11,17,21)$. However, criticisms have been made regarding the poor standardization of QoL scales, and the frequent inappropriate use of the term QoL (17). The use of a one-item scale to assess general QoL (the IPSS-QoL question, called "bother score"), and the misinterpretation of QoL as synonym of symptom-control, or perceived general health or functional status, are the most frequent reasons for such criticisms $(1,9,17,21)$.

In the present study, two QoL scales validated by the WHO (one especially developed to assess the geriatric population) were used $(19,20)$. Over the last ten years, despite descriptions of associations between LUTS and advancing age, with increasing discomfort, impairment of daily activities and perception of poor health, few texts were specifically focused on elderly men, and none adopted the WHOQoL-Old $(3,5,22)$.

All domains and facets evaluated by both QoL questionnaires, with the exception of the first question of WHOQoL-Bref, reached results that differed statistically between the two groups, with lower QoL scores in group I. The items assessed by WHOQoL-Bref with lower $\mathrm{p}$ value $(\mathrm{p}<0.0005)$ were observed in the domains "social relationships", "environment", and the question "self-satisfaction with his own health" ( $p<0.0001)$. Among WHOQoLOld results, the facet "social participation" and the Old score presented the lowest $p$ values $(<0.0005)$. These results can be compared with the findings of two studies that applied the SF-36 questionnaire to men with LUTS and/or BPE. In the first study, the IPSS and SF-36 were used to evaluate 189 patients on the waiting list for surgical treatment for BPE, who presented worse perceptions of QoL than the general population of similar age, in direct relation to increasing severity of irritative symptoms (7). Social functioning was the parameter of best performance, and role-physical was the worst one. The second study employed the SF-36 and the American Urological Association Symptom Index, and the main losses of QoL were in energy and vitality, general health perception and overall physical dimension (10). Significant worsening of social functioning of individuals with LUTS was not identified, and the authors reasoned this result might have been due to inadequacy of the SF-36 for recognizing the social impact caused by LUTS. Besides such studies evaluated men whose mean age was $68.8 \pm 6.9$ and $61.9 \pm$ 9.1 years, none was designed to evaluate a geriatric population.

Another study evaluated 480 men referred for urological consultation, using the WHOQoLBref and the IPSS (23). There was no exclusive selection of elderly patients, and the only QoL domain impaired by increasing LUTS was physical health. Such article concludes that WHOQoL-Bref would be too comprehensive to identify associations between specific symptom-related factors, and LUTS suggestive of BPE and LUTS-associated factors would not be important determinants of QoL.

The present study signals that older men are particularly sensitive to the impact of LUTS on their QoL, because all domains and facets of QoL analyzed by WHOQoL-Bref and WHOQoL-Old had significantly lower scores among moderate to severe-symptomatic patients. These findings corroborate for the existence of important QoL indicators for the elderly, which are not evaluated on general QoL scales for adults; studies that make no distinction between different age groups may be unable to recognize differences in QoL impairment related to age. Additionally, older men's perceptions of the impact of LUTS on their QoL extend not only to parameters straightly determined by urinary symptoms. Members of group I presented worse performances in sensory functioning and perception of death and dying, which do not seem to have any direct/causal relationship with LUTS. The psychological impact of LUTS on elderly men might lead to poor self-perception of QoL, and group I members did present lower scores in psychological domains, while LUTS-related psychological aspects have already been described elsewhere $(24,25)$. However, in the present study, similar 
scores for depression and anxiety were recorded for the two groups. Hence, whether self-depreciation of QoL is cause or consequence of LUTS-related psychological factors can not be described here.

Finally, this study leads to reflections on the importance of proper assessment of moderate LUTS men. Group I joined moderate and severe LUTS patients, but its mean IPSS was $15.83( \pm 6.3)$, which suggests that the results could be extrapolated for moderate symptomatic patients. Surgical treatments are predominantly indicated for severe-symptomatic patients, and watchful waiting or conservative measures are indicated for patients with mild complaints $(2,14,26)$. However, therapeutic choices for moderate cases are frequent source of doubts among urologists, especially in the presence of co-morbidities. Recognition of significant deterioration of QoL among moderate LUTS patients is an evidence for the need of treatment (as opposed to waiting approaches), and justification for early surgery (26).

The similarity of answers to the self-rated QoL question (WHOQoL-Bref n.1) only represents an apparent contradiction. The answers to 49 of 50 questions that compose the two QoL questionnaires presented lower scores in group I, besides around $90 \%$ of all participants declared that their QoL was "good" or "neither bad nor good". This inconsistency exemplifies that a single question for QoL assessment may not reflect the results obtained with comprehensive scales (17).

In regards to potential problems and limitations, the population studied was not a true random sample of elderly men, which allows the possibility of selection bias. The role of specific comorbities, the analysis of age subgroups, and clinical implications of the results obtained were not evaluated. Potential differences between moderate and severe LUTS patients could not be determined precisely, because they were joined in the same group.

\section{CONCLUSIONS}

Men aged 65-years or over with moderate/ severe LUTS have worse QoL ratings for almost all evaluation parameters proposed by the World Health Organization, according to the WHOQoLBref and WHOQoL-Old instruments, especially social and environmental relationships, compared with mildly symptomatic or asymptomatic men in the same age group.

\section{CONFLICT OF INTEREST}

None declared.

\section{ABBREVIATIONS}

BPE - Benign prostatic enlargement

CI - Confidence interval

HADS - Hospital Anxiety and Depression Scale

IPSS - International Prostate Symptom Score

LUTS - Lower urinary tract symptoms

MW - Minimum wages

QoL - Quality of life

SD - Standard deviation

WHO - World Health Organization

WHOQoL - World Health Organization Quality of

Life

\section{REFERENCES}

1. Fitzpatrick JM: The natural history of benign prostatic hyperplasia. BJU Int. 2006; 97(Suppl 2):36; discussion 21-2.

2. Burnett AL, Wein AJ: Benign prostatic hyperplasia in primary care: what you need to know. J Urol. 2006; 175: S19-24.

3. Medina JJ, Parra RO, Moore RG: Benign prostatic hyperplasia (the aging prostate). Med Clin North Am. 1999; 83: 1213-29.

4. Girman CJ, Jacobsen SJ, Tsukamoto T, Richard F, Garraway WM, Sagnier PP, et al.: Health-related quality of life associated with lower urinary tract symptoms in four countries. Urology. 1998; 51: 428-36.

5. Trueman P, Hood SC, Nayak US, Mrazek MF: Prevalence of lower urinary tract symptoms and selfreported diagnosed 'benign prostatic hyperplasia', and their effect on quality of life in a communitybased survey of men in the UK. BJU Int. 1999; 83: 410-5.

6. Bertaccini A, Vassallo F, Martino F, Luzzi L, Rocca Rossetti S, Di Silverio F, et al.: Symptoms, bothersomeness and quality of life in patients with LUTS suggestive of BPH. Eur Urol. 2001; 40 (Suppl 1): $13-8$. 
7. Salinas-Sánchez AS, Hernández-Millán I, LorenzoRomero JG, Segura-Martin M, Fernández-Olano C, Virseda-Rodriguez JA: Quality of life of patients on the waiting list for benign prostatic hyperplasia surgery. Qual Life Res. 2001; 10: 543-53.

8. Quek KF, Loh CS, Low WY, Razack AH: Quality of life assessment before and after transurethral resection of the prostate in patients with lower urinary tract symptoms. World J Urol. 2001; 19: 358-64.

9. Yoshimura K, Arai Y, Ichioka K, Terada N, Matsuta Y, Okubo K: Symptom-specific quality of life in patients with benign prostatic hyperplasia. Int J Urol. 2002; 9: 485-90.

10. Welch G, Weinger K, Barry MJ: Quality-of-life impact of lower urinary tract symptom severity: results from the Health Professionals Follow-up Study. Urology. 2002; 59: 245-50.

11. Bobé Armant F, Buil Arasanz ME, Allué Buil AI, Morro Grau A, Maxenchs Esteban M, Gens Barberà M: Benign prostate hyperplasia. Need to evaluate quality of life in the therapeutic process]. Aten Primaria. 2006; 38: 387-91.

12. Barry MJ, Fowler FJ Jr, O'Leary MP, Bruskewitz RC, Holtgrewe HL, Mebust WK, et al.: The American Urological Association symptom index for benign prostatic hyperplasia. The Measurement Committee of the American Urological Association. J Urol. 1992; 148: 1549-57; discussion 1564.

13. Rodrigues P, Meller A, Campagnari JC, Alcântara D, D'Império M: International Prostate Symptom Score-IPSS-AUA as discriminat scale in 400 male patients with lower urinary tract symptoms (LUTS). Int Braz J Urol. 2004; 30: 135-41.

14. Barry MJ, Mulley AG Jr, Fowler FJ, Wennberg JW: Watchful waiting vs immediate transurethral resection for symptomatic prostatism. The importance of patients' preferences. JAMA. 1988; 259: 3010-7.

15. Fowler FJ Jr, Wennberg JE, Timothy RP, Barry MJ, Mulley AG Jr, Hanley D: Symptom status and quality of life following prostatectomy. JAMA. 1988; 259: 301822.

16. Cockett AT, Aso Y, Denis L, Khoury S, Barry M, Carlton CE, et al.: World Health Organization Consensus Committee recommendations concerning the diagnosis of BPH. Prog Urol. 1991; 1: 957-72.

17. Haltbakk J, Hanestad BR, Hunskaar S: Use and misuse of the concept of quality of life in evaluating surgical treatments for lower urinary tract symptoms. BJU Int. 2003; 91: 380-8.

18. Marcolino JA, Mathias LA, Piccinini Filho L, Guaratini AA, Suzuki FM, Alli LA: Hospital Anxiety and Depression Scale: a study on the validation of the criteria and reliability on preoperative patients. Rev Bras Anestesiol. 2007; 57: 52-62.

19. [No authors listed]: The World Health Organization Quality of Life Assessment (WHOQOL): development and general psychometric properties. Soc Sci Med. 1998; 46: 1569-85.

20. Fleck MP, Chachamovich E, Trentini C: Development and validation of the Portuguese version of the WHOQoL-Old module. Rev Saude Publica. 2006; 40: 785-91.

21. O'leary MP: Validity of the "bother score" in the evaluation and treatment of symptomatic benign prostatic hyperplasia. Rev Urol. 2005; 7: 1-10.

22. Vela-Navarrete R, Alfaro V, Badiella LL, FernándezHernando N: Age-stratified analysis of I-PSS and QoL values in spanish patients with symptoms potentially related to BPH. Eur Urol. 2000; 38: 199-207.

23. Haltbakk J, Hanestad BR, Hunskaar S: How important are men's lower urinary tract symptoms (LUTS) and their impact on the quality of life (QOL)? Qual Life Res. 2005; 14: 1733-41.

24. Quek KF, Low WY, Razack AH, Loh CS: The psychological effects of treatments for lower urinary tract symptoms. BJU Int. 2000; 86: 630-3.

25. Quek KF, Razack AH, Chua CB, Low WY, Loh CS: Effect of treating lower urinary tract symptoms on anxiety, depression and psychiatric morbidity: a oneyear study. Int J Urol. 2004; 11: 848-55.

26. Wasson JH, Reda DJ, Bruskewitz RC, Elinson J, Keller AM, Henderson WG: A comparison of transurethral surgery with watchful waiting for moderate symptoms of benign prostatic hyperplasia. The Veterans Affairs Cooperative Study Group on Transurethral Resection of the Prostate. N Engl J Med. 1995; 332: 75-9.

Submitted for publication:

August 27, 2010

Accepted after revision:

April 11, 2011

\section{Correspondence address:}

Dr. Vitor Last Pintarelli

R. Gabirobas, 12 / 54

Curitiba, PR, 81560-150, Brazil

Fax: +55 41 3253-4178

E-mail: vitorpintarelli@yahoo.com.br 